\title{
VISUALISATION-ASSISTED TEACHING: CAN VIRTUAL GIVE RISE TO REAL KNOWLEDGE?
}

Todar Lakhvich

Belarusian State Pedagogical University named after Maxim Tank, Republic of Belarus E-mail: bntu71@gmail.com

There are two main different ways of reasoning (Harnad, 1987). For most people it's natural to do their reasoning on the semantic level. Graphic tools have always played an important part in this reasoning style. When using a formal and abstract language and exact rules governing the creation and transformation of statements in this language, one reveals the ability to work on the syntactic level. And this can be postulated as a quite different way of reasoning, which is based almost exclusively by the logicians. The use of graphic forms in this case is also possible, though it requires more time and technological complexity. For exact sciences, primarily mathematics based, the use of computers can raise the efficiency of the method. Still for Sciences, e.g. Chemistry, even before the informational revolution the special interconversion tools between empirical knowledge and different types of reasoning had been developed, the latter originates from the very core of Science knowledge. Based on the experiment (the initial stage was almost completely empirical) the Science gained the new paradigm which rather formal by nature and fundamental in methodological meaning. Interconversion between empiric and theoretical moieties seems to be the core point of the consideration.

The visualization is to be the core element for the modern Educational model and Paradigm for Science. This category is sometimes associated with the problem of modeling, which is one of the most important in modern chemistry. Still the discussion in many aspects manifested the initial stage of the recognition, models mostly being discussed in terms of molecular recognition and computational modeling.

Models are used in all scientific disciplines. It's worthy to note they are appropriate not only for theoretical considerations but useful in the framework of more practically oriented fields of Chemistry. The typology of models has been developed regarding the hierarchy of the latter in dependence of their relative similarity (Tomasi, 1988) and includes material, abstract, symbolic, analogical and iconic patterns. For effective teaching models need to be adequate, effective, contemporary, exciting, and finally appropriate for successive usage (taking into account the need for continuity of education). The similarity between real objects and models can almost be neglected in this context. To create an effective didactic model, we need to accept the influence of many features and conditions, which include both the nature of real objects and didactic (for the academic disciplines) aspects. We consider the category of visualization is more comprehensive and can be discussed in various aspects, some of them are all-pervading philosophy principle, psychological tool for cognition and finally the model having for chemistry its own complex structure.

More theories do not always mean the effective Education. Does visualization really help to teach more effectively (and learn in easier way!)?

A few years ago we carried out the research, which was practically oriented to advance the education process when teaching Hearing-Impaired Students (Lakhvich, 2009). The 
PROBLEMS

OF EDUCATION

IN THE $21^{\text {st }}$ CENTURY

volume 42, 2012

theoretical background of the study is interdisciplinary and grounded both in social semiotic perspective (Vygotsky, 1978 and his followers Wertsch, 1990 and Lemke, 1991) and conceptual and practically-oriented inquiries made by group of chemistry philosophers and chemists (one out of them is the author) in the period of last decade.

According to Vygotsky, the interrelatedness of thought, action and semiotic tools is fundamental to development. Our educational interactions reflect the surrounding culture, and thus, our learning becomes a social process. Hearing impaired (HI) students have differences in cognition development (speech impairments, specificity of cognition development: perception, memory, thinking, etc.) because of primary deprivation of aural sensor. In the case the rest sensors obviously ought to compensate the loss of aural one, and visual sensor seems to be the main among the alternative pathways. The substitution of the aural-assisted mechanism of information transfer leads to "double burden" to other sensors, and thus, requires specific forms of learning to avoid psychological crisis. In the case the usage of various types of visualization techniques seems to be a good alternative to verbal communication.

The investigation included different forms of visualization-based educational techniques: various models, animations, chemistry experiment, play-therapy, etc.

Animations assisted different topics of general course and the emphasis was made to form a visual-based acceptance of chemistry information, regarding the attractiveness and agerelated accessibility of the models proposed. Thus, the concept of valency was visualized in form of 4-handed (for Carbon), 3-handed (for Nitrogen), 2-handed (for Oxygen) and finally 1-handed (for Hydrogen and Halogens) manikins. They were allowed to form chemical bonds and structure taking into account their valency/handy-capacity. Discussing topics from organic chemistry the isomerism of organic compounds was visualized in the same manner, in addition various animals were proposed as the imaginary models of chemical elements. The initial introduction of visualized social and/or domestic patterns followed by the interchange of the latter for geometrical figures grouped in proper manner and finally to structural formulae. The special attention was made to use of condensed visualization technology elaborated earlier and accessed for regular pre-university and university students.

The approach had been pursued in the framework of game-learning therapy. The latter included students cast, which played elements forming chemical bonds. The game enhanced the usage of additional sensors accessible for deaf students (visual, tactile and kinaesthetic). The positive motivation facilitated study process.

Investigations showed great motivation of HI students to carry out experiments in school laboratory. The latter obviously correlates with the fact that impairing hearing has little effect on the ability to work in the laboratory. Moreover, circumstances are favourable for such students to realise their potential in science. We used the potential of the chemical experiments both in individual and collective forms. The latter was supplemented with graphic presentations, 3Danimations, molecular modelling and play therapy activity. Visualization-assisted technologies also enhances positive motivation for learning chemistry and other Science disciplines.

Just results obtained with HI students (the population of the research can be regarded as the model for other students: having closed gates to some receptors they use more effectively visual techniques!) revealed the potential of visualisation in Science Education. Still, the better visualization seems to be close in patterns proposed to real life. So searching for new techniques never forget about real life. 


\section{References}

Harnad, S. (1987). Category Induction and Representation. In: Categorical Perception: The Groundwork of Cognition. New York: Cambridge UniPress.

Tomasi, J. (1988). Models and modelling in theoretical chemistry. Journal of Molecular Structure (Theochem), 179, 273-292.

Vygotsky, L. S. (1978). Mind in society: the development of higher psychological processes. Cambridge. MA: Harvard Uni. Press.

Wretch, J. V. (1991). Voices of the mind: A sociocultural approach to mediated action. Cambridge. MA: Harvard Uni. Press.

Lemke, J. I. (1990). Talking science: Language, learning and values. Norwood. NJ: Ables.

Lakhvich, T., Traunikava, V., Efimava, A. (2007). Condensed Visualization Technology for Effective Teaching Chemistry. In: V.Lamanauskas \& G.Vaidogas (Eds.), Science and Technology Education in the Central and Eastern Europe: Past, Present and Perspectives (The proceedings of $6^{\text {th }}$ IOSTE Symposium for Central and Eastern Europe). Siauliai: Siauliai University Press, pp. 72-79.

Lakhvich, T., Kostareva, A., Lehankova, V. (2009). Visualisation-Assisted Chemistry Teaching of Hearing-Impaired Students. In: M. Bilek (Ed.), Research, Theory and Practice in Chemistry Didactics. Hradec Kralove: Gaudeamus, pp. 221-22.

Received: April 28, 2012

Accepted: May 02, 2012

Todar Lakhvich

$\mathrm{PhD}$, Associate Professor, Belarusian State Pedagogical University

named after Maxim Tank, Republic of Belarus.

E-mail: bntu71@gmail.com 